\title{
THE ROLE AND INFLUENCE OF WINE AWARDS AS PERCEIVED BY THE SOUTH AFRICAN WINE CONSUMERS
}

\author{
Prof FJ Herbst: University of Stellenbosch Business School
}

\section{Christiane von Arnim: University of Stellenbosch Business School}

\begin{abstract}
Purpose: The purpose of this study was to examine whether, in the mind of the consumer, wine awards do indeed play a significant role in influencing consumer choices. Initially, a literature review was conducted to establish the role of wine awards in wine marketing.
\end{abstract}

Problem investigated: The increasing number of wine competitions appears to dilute the value of wine awards as a marketing tool. The local wine consumers are currently bombarded by a variety of wine choices and need to use cues to assist them in making buying decisions. Consumers are also sceptical about the honesty of producers in marketing their awards.

The question arises, whether, in the minds of South Africa's wine consumers, awards play a strong enough role in influencing their choice when buying wine.

Research design: A convenience sample was drawn among South African wine consumers by using an online survey questionnaire. A sample of 285 was realised and the data analysed by using descriptive and inferential statistical methods.

Findings and implications: Wine awards are indeed recognised by the consumer as a cue that shapes their choices/selection criteria, but their importance is relatively low compared to other cues such as variety, vintage, producer, production method, packaging, place of origin and price. Yet, having established that decision-making is a complex set of interactions, wine awards do nevertheless play a role in supporting a decision in certain circumstances and for certain customer segments.

Generally speaking, it was found that the more sophisticated a consumer (connoisseur) is the less regard exists for wine awards. Not only do wine awards have lesser power in shaping decisions, but also attitudes towards the concept of wine awards are more negative. Lesser informed consumers tend to take more guidance from, and are less opinionated about the concept of wine awards.

An independent monitoring authority is seen as a solution to raise the profile of wine awards in South Africa, thus creating more credibility and power for this tool.

Value of the research: Although a representative sample was not drawn, the wine consumers included in this study strongly suggested that an independent authority is needed to monitor wine awards in South Africa. This could enhance the value of wine awards as a marketing tool, whilst wine awards and medals should be aimed at the less informed segments of the local market.

Conclusion: The study revealed that while wine awards are indeed recognised by the majority of consumers as a cue that shapes their choices, the importance thereof is relatively low compared to other elements of the marketing mix. Wine producers and marketers should use wine awards only to support other quality claims.

Key words: Role of wine awards, wine purchasing and consumer decision-making

\section{INTRODUCTION AN BACKGROUND}

In recent years, the South African wine market has become increasingly competitive as more and more wine brands enter the market every year. The local market environment has been characterised by stagnant demand for years (McGregor, 2007: 4) and over the past two years, per capita wine consumption has in fact been on the decline, reaching a level of only 7,7 litres per consumer per year (Van Zyl, 2006: 8). Producers across the board are experiencing slim margins due to increasing price competition (McGregor, 2007: 4) and consequently they are under more pressure than ever to gain an edge over others by proposing a sufficiently convincing argument to induce purchase.

A thorough understanding of how consumers choose wine is required for marketing decisions surrounding pricing and distribution, as well as the allocation of resources to packaging, merchandising and advertising (Lockshin and Hall, 2003). The need for effective and efficient marketing decisions is 
particularly relevant within the competitive South African wine industry where producers are fighting for market share while profit margins are declining (McGregor, 2007: 4).

The elements that are predominantly involved in creating the look and feel of wine packaging are the bottle size and shape, the cork, the capsule, and most importantly the label (Thomas, 2000: 56). Over and above these elements, producers frequently indicate various awards that a particular wine has won to create greater product appeal. Medal stickers - typically through little gold, silver or bronze labels - are added to the face of the bottle and other forms of communication, e.g. magazine articles, adverts and newsletters are frequently used in addition to communicate such achievements to consumers.

The Veritas Award is the longest running wine competition in South Africa and it has attracted the largest number of entries of market-ready wines since 2006. According to the organisers, the award "gives recognition to wines of exceptional quality and the distinctive Veritas symbol of excellence serves as an authoritative quality guideline for wine connoisseurs. Gold and double gold awards are of significant value to the wine industry as well, as it offers a prestigious image for the wine, winery and winemaker and contributes to growth in sales" (www.veritas.co.za). Numerous other South African wine awards have sprung up over the years, claiming similar philosophies and benefits. Amongst these are the Michelangelo International Wine Awards, Fairbairn Capital/Old Mutual Trophy Wine Show, ABSA Top 10 Pinotage Competition, and so on. Additionally, several international wine competitions, such as the London International Wine and Spirit Competition, the Decanter Trophy and Concours Mondial de Bruxelles, are vying for producers' sample submissions and their substantial entry fees for these submissions.

In response, South African wine writer Neil Pendock (2006) has already indicated his suspicion that competition organisers are in fact the "main beneficiaries" of the wine show business, as the value for producers and consumers declines. Similarly, Orth (2002: 82) observed that the increasing multitude of awards dilutes the distinguishing benefits associated with each and hence that their effectiveness as an indicator of value declines.

Comments like these raise the question of what leaves producers and consumers in the context of the superfluous number of wine awards and whether the ultimate aim is achieved, namely to differentiate brands on the basis of their quality associations.

\section{LITERATURE REVIEW}

\section{Factors influencing the choice of wine}

The consumer's choice of wine is influenced by push, pull, exogenous, cost and time factors (Orth \& Krska, 2002). The push factors include psychological motives such as hedonism, relaxation, value for money, celebration and sociability. The pull factors include the grower's reputation, grape variety, price, label, and production method and health aspects. Exogenous factors include the shopping and consumption environment and legal regulations. Time frame factors include the amount of shopping time available and consumption time, whilst the total cost factors may include real and perceived costs such as the cost of purchase, product cost, use cost, disposable cost and social cost risk.

\section{Benefits sought in wine}

Consumers also seek to derive certain benefits from purchasing and consuming wine. According to Spawton (1991) these benefits can be divided into core benefits and tangible and intangible features. Wine awards are associated with the intangible benefits sought by the wine buyer. From a marketing and sales point of view, opinions differ with regard to the type of medals that are necessary to boost sales.

\section{Perceived risks in wine purchasing}

Orth (2002: 81) has shown that in the Czech Republic, consumers generally perceive the quality of a wine to be higher when it has been officially endorsed by a group of experts. Consumers do however not seem to question the validity and credibility of these judgments, as most of the respondents indicated that their lack of familiarity with the judges and the judging process is irrelevant to them. It therefore appears 
that some consumers are easily prepared to pass on the responsibility for their purchasing decisions to a third party without further enquiry.

\section{The specific role of wine awards in decision-making}

According to Orth (2002: 80), wine awards have become a particularly popular means of signalling superior quality and value to the consumer and he concludes that wine awards are salient product features in the formation of consumer preferences, particularly among less informed buyers. Wine awards thus serve as an important element in the "communication" of brand benefits to the consumer. Since wine purchasing decisions are frequently unplanned and hence take place with little prior information gathering, the medal stickers and the indication of scores achieved by third party ratings add an important cue to the packaging that helps shape the customer's perceptions of the wine's quality, in the absence of the ability to taste the product.

It was established that in fact the appearance of any sticker or sticker-like element as part of the packaging suffices to enhance the quality image of a wine. This effect was observed in the cases of some producers, who changed their labels to include a round element that resembled the appearance of a gold award (Minaar, 2005). Such actions demonstrate that "cheating" seems to be worthwhile for producers, and that indeed the perceptions that are derived from the mere appearance of the bottle and label are very powerful in influencing decision-making. It appears that consumers frequently pay no particular attention to the information contained on the medal sticker, but simply respond to the cue of a round golden shape.

However, generalisations are difficult as responses towards the various packaging elements are complex and frequently dependent on a number of circumstances. For example, Lockshin, Jarvis, d'Hauteville and Perrouty (2006: 173) found that in cases where the brand is relatively unknown and sold at a low price perhaps a newcomer in the market - a gold medal has a distinctly positive impact on market share. This effect is significantly amplified when the wine comes from a reputable growing region. Well-known brands on the other hand seem to enjoy the greatest merit based on the strength of their brand alone. It appears that elements such as medals or a reputable growing region do not impact as strongly on sales of well-known brands as they do with unknown brands.

Opinions differ with regard to the type of medals that are necessary to boost sales. Joubert (2005) states that many producers only emphasise the achievement of trophies or double gold awards, whilst disregarding bronze medals altogether. It is therefore questionable whether bronze or silver medals have any impact on the consumer.

Lockshin et al. (2006: 167), Orth (2002: 81) and Orth and Krzka (2002: 387) take a more differentiated approach in their respective studies, and have in fact identified differences in the impact of gold versus silver medals on consumer behaviour. Different grades and origins of medals are perceived differently than other variables, such as price, variety, brand name, etc.

\section{Wine segmentation}

Spawton (1991: 17) identified four major psychographic groupings along which the wine market can be segmented: connoisseurs, aspirational drinkers, beverage wine consumers and new wine drinkers.

- Connoisseurs - Expert wine drinkers with strong preferences for particular brands. Buying wines is based on specific, predetermined criteria such as variety, origin and the vinification process. Wine is an important part of their lifestyles.

- Aspirational wine drinkers - Mostly concerned with the social aspects of wine drinking. Wine tends to be a fashion and status symbol. Typically, they read or listen to the advice of third parties to guide them in deciding which wines to buy.

- $\quad$ Beverage wine drinkers - Have little desire for wine appreciation. They prefer to purchase brands they know as offering a desirable taste at a good price. Brand loyalty plays the main role in their buying decisions.

- $\quad$ New wine drinkers - Young adults who are attracted to wine because of peer group influences. The typical occasion for wine drinking is at parties and pubs. Most of their drinking is likely to take place by the glass. The bottle and, hence, sophisticated information about wines play a minimal role in choosing a wine. Due to the low level of sophistication, price is often the determinant of 
choice. Since most of this consumption is likely to take place on a "by the glass" basis - i.e. without sight of the bottle, it can be assumed that in this context, wine awards are somewhat irrelevant. This segment was excluded from the analysis of the study.

\section{THE RESEARCH QUESTION}

The question can be raised whether, in the minds of South Africa's wine consumers, awards play a strong enough role in influencing their choice when buying wine.

\section{THE RESEARCH OBJECTIVES}

The primary research objective was to establish the local consumers' perspective on the relevance of wine awards.

The secondary research objectives were to:

- $\quad$ determine the role wine awards play in shaping consumer decision-making;

- $\quad$ determine which local wine award is seen as the most authoritative;

- $\quad$ determine the perceived credibility and fairness of wine awards;

- $\quad$ investigate the ability of wine awards to act as a guideline of quality;

- $\quad$ determine whether wine awards reduce perceived risks in wine purchasing;

- $\quad$ determine whether the increasing multitude of wine awards lead to confusion;

- $\quad$ determine whether international medals have a greater impact than local medals.

\section{HYPOTHESES}

Based on the evidence in the literature, the following hypotheses were formulated:

$\mathbf{H}_{1}$ : There are differences in the relative importance of wine awards between the three consumer segments.

$\mathbf{H}_{2}$ : There are differences in perceptions between different consumer segments regarding the contribution that wine awards and medal stickers make in aiding decision-making.

$\mathbf{H}_{3}$ : The relative importance assigned to wine awards differs between purchasing occasions.

\section{RESEARCH METHODOLOGY}

\section{Questionnaire design}

Guidance was taken from questionnaires used in past studies in related fields, such as studies by Orth and Krzka (2002: 385 - 397) and Mitchell and Greatorex (1989:31 - 46). An item review was done amongst selected faculty members of the University of Stellenbosch Business School and the pre-testing conducted amongst a group of $35 \mathrm{MBA}$ students, who were asked to respond to the survey and to state any difficulties that they encountered in the process. Feedback received during the pre-testing also made necessary the shortening of question re-phrasing of certain statements, which were identified as misleading or confusing by the test group.

The final on-line questionnaire was designed to serve as a data collection tool for measuring the relative intensity of feelings and attitudes amongst wine consumers in South Africa. A five-point Likert-type scale was developed ranging from "strongly disagree" to "strongly agree". Such scales have proven to be very successful in determining consumer attitudes and perceptions in self-administered questionnaires (Aaker, Kumar \& Day, 2000: 284; Churchill and lacobucci, 2005:264; and Patten, 2001:33). Evidence of its wide use is provided in wine marketing literature, where five-point scales were for example been applied by Orth and Krzka (2002:394).

The final on-line questionnaire consisted of the following three sections:

\section{Section 1: Demographic information}

This section aimed at gathering demographic information such as gender, age, place of normal residence. Closed ended questions were used and the respondents could select the appropriate options through checkboxes and drop-down boxes on the on-line questionnaire. 


\section{Section 2: $\quad$ Wine consumption and decision-making}

This section aimed at gaining more insight into the wine consumer type and the decision-making process that the respondent generally applies when buying wine. Information pertaining to consumption volume was based on Spawton's (1991: 17) four major psychographic groupings. The degree of involvement was required for further segmentation purposes, while questions relating to the factors considered during decision-making identified the relative importance of wine awards within different scenarios. In addition, the kind of questions in this section helped to ease the respondent into wine-related thought patterns, which would help answering the questions in the last section, covering wine awards specifically.

\section{Section 3: $\quad$ Ratings of specific awards}

This section aimed at establishing consumer opinions and attitudes about wine awards in general and certain awards in particular. In an effort to optimise the structure of the questionnaire, attitude and opinion related items were placed into the same table, which was made possible by designing the statements in such a way that they could all be answered on the same "Strongly disagree - Strongly agree" scale. Some of the statements were developed by the researcher, while others were derived from Orth and Krzka's (2002: 385 - 397) study in the Czech Republic.

The main attitude dimensions measured were:

- Perceived credibility and fairness in the execution of wine awards.

- Perceived ability of wine awards to support decision-making.

- The ability of wine awards to reduce perceived risk.

- The perceived consumer benefit from wine awards.

The following opinions and topics were captured in addition to the attitude dimensions above:

- Whether the increasing number of wine awards is confusing.

- Whether international competitions are considered more prestigious than South African awards.

- Whether consumers feel there is a need for an independent competition monitoring authority.

- Whether gold medals are considered significantly more important than silver medals.

- Whether consistent performance at wine awards is deemed to be important.

\section{Sampling and data collection}

Non-probability sampling was used through the application of a purposive sampling technique. An online survey was selected based on the $11-30 \%$ response rate for online surveys predicted by Saunders et al. (2007: 358). The desired number of responses was 384 and given an expected response rate of 11 $30 \%$, the questionnaire needed to be exposed to at least 1280-3490 users of wine portals. These selected wine portals were:

- $\quad$ www.wine.co.za - a provider of news from the wine industry;

- Wine of the Month Club - a wine marketing and distribution company, www.grape.co.za (an online wine enthusiast community);

- $\quad$ www.facebook.com, a social utility; home to the South African Wine Lovers Group; and

- $\quad$ www.winemag.co.za a monthly wine publication.

A self-administered internet questionnaire was made available and advertised on the abovementioned portals for completion on-line from 25 February to 14 March 2008.

\section{Data capturing and analysis}

All data fields were named and pre-coded so that all responses were automatically captured in a single MS Access database. Subsequently, the file was converted into an MS Excel to perform statistical analyses. The data was analysed using descriptive and inferential statistical methods seeking to determine differences between consumer groups and occasions and analyses were performed at a $95 \%$ level of confidence. 


\section{RESEARCH RESULTS}

\section{Response rate}

A total of 285 responses were gathered through the abovementioned on-line portals/distribution channels.

\section{Respondent profile}

Table 1 below describes respondent profile based on gender, type of segment and wine consumption per week.

Table 1: $\quad$ Respondent profile

\begin{tabular}{|c|c|}
\hline & Percentage of the sample \\
\hline \multicolumn{2}{|l|}{ Gender } \\
\hline Male & $55 \%$ \\
\hline Female & $45 \%$ \\
\hline \multicolumn{2}{|l|}{ Segment } \\
\hline Connoisseurs & $25 \%$ \\
\hline Aspirational wine drinkers & $66 \%$ \\
\hline Beverage wine drinkers & $9 \%$ \\
\hline New wine drinkers & $0 \%$ \\
\hline \multicolumn{2}{|c|}{ Wine consumption per week } \\
\hline One bottle or less & $24 \%$ \\
\hline Two to three bottles & $49 \%$ \\
\hline Four or more bottles & $27 \%$ \\
\hline
\end{tabular}

As depicted in Table 1 the majority of respondents were male, aspirational drinkers and consume two to three bottles of wine per week.

\section{The role of wine awards in shaping consumer decision-making}

A wine's variety is considered the most important cue (4.14), followed by a wine's vintage and producer rank with mean values of 3.75 and 3.58 , respectively.

Table 2: $\quad$ Importance of marketing cues

\begin{tabular}{|l|c|}
\hline \multicolumn{1}{|c|}{ Cue } & Mean value \\
\hline Variety & 4.14 \\
\hline Vintage & 3.75 \\
\hline Producer & 3.58 \\
\hline Production method & 3.33 \\
\hline Attractive packaging & 3.19 \\
\hline Region & 3.03 \\
\hline Awards & 2.97 \\
\hline Low price & 2.48 \\
\hline
\end{tabular}

Special note: A 5 point Likert scale was used, where $5=$ extremely important and $1=$ not important at all Wine awards with a mean value of 2.97 are rated as relatively unimportant compared to other marketing cues and play a secondary role in shaping consumer decision-making. 


\section{Local and international wine awards}

Respondents were asked to select those South African wine awards they perceived to be most authoritative in the sense of serving as a suitable quality guideline. The annual Veritas Wine Awards were considered to be the most authoritative local wine award, followed by the Michelangelo International Wine Awards, Old Mutual Trophy Wine Show and Diners Club Winemaker of the Year Awards.

Table 3 below depicts various opinions regarding wine awards.

Table 3: $\quad$ Opinions about wine awards

\begin{tabular}{|l|c|c|}
\hline \multicolumn{1}{|c|}{ Opinion } & $\begin{array}{c}\text { Strongly } \\
\text { disagree }\end{array}$ & $\begin{array}{c}\text { Strongly } \\
\text { agree }\end{array}$ \\
\hline The increasing number of wine awards is confusing & $15 \%$ & $68 \%$ \\
\hline $\begin{array}{l}\text { International competitions are considered more prestigious compared to } \\
\text { South African wine awards }\end{array}$ & $24 \%$ & $50 \%$ \\
\hline Gold medals are considered significantly more important than silver medals & $35 \%$ & $40 \%$ \\
\hline
\end{tabular}

Special note: A 5 point Likert scale was used, where $5=$ Strongly agree and $1=$ Strongly disagree

It is clear from Table 3 above that the majority $(68 \%)$ of the respondents strongly agreed that the increasing number of wine awards is confusing. South African awards are regarded as less important than international awards and there are no differences between the value attached to gold and to silver medals.

\section{Confusion caused by wine awards}

Figure 1 below illustrates that $66 \%$ of respondents (26\% strongly agreed and $42 \%$ agreed) regarded the increasing number of wine awards as confusing.

Figure 1: $\quad$ Confusion caused by wine awards

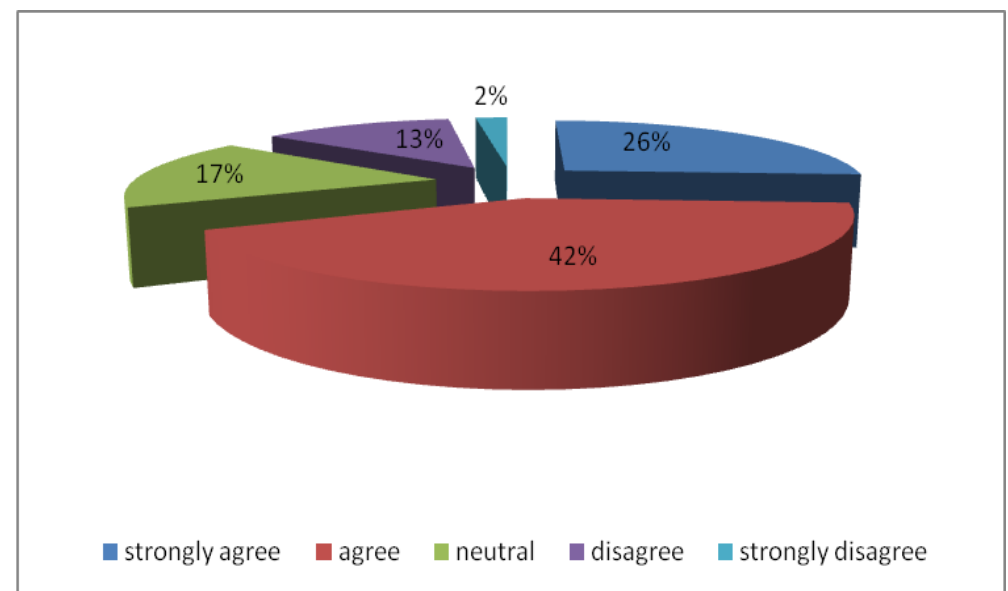

\section{Attitudes and opinions about wine awards}

The underlying attitude dimensions tested were:

- $\quad$ perceived credibility and fairness in the execution of wine awards;

- $\quad$ perceived ability of wine awards to act as a quality guide;

- $\quad$ perceived ability of wine awards to reduce risk; and 
- $\quad$ perceived consumer benefit from wine awards.

The mean values per dimension and statement are listed in Table 4 below. It is clear from the mean values that the respondents had the strongest attitude/feeling towards the perceived credibility and fairness of wine awards (3.590), followed by perceived consumer benefit from wine awards (3.200), the perceived ability of wine awards to reduce risk (2.873) and perceived ability of wine awards to act as a quality guide (2.836).

Table 4: $\quad$ Mean values for attitudinal dimensions and statements

\begin{tabular}{|l|c|}
\hline \multicolumn{1}{|c|}{ Dimension and statements } & Mean value \\
\hline Perceived credibility and fairness of wine awards & $\mathbf{3 . 5 9 0}$ \\
\hline $\begin{array}{l}\text { Judges at wine competitions are well capable of objectively assessing the quality } \\
\text { of a wine. }\end{array}$ & 3.510 \\
\hline $\begin{array}{l}\text { Some producers deliberately try to mislead consumers with labels that look like } \\
\text { awards. }\end{array}$ & 3.640 \\
\hline Wine producers often make false claims with regard to awards they have won. & 3.610 \\
\hline Perceived ability of wine awards to act as a quality guideline & $\mathbf{2 . 8 3 6}$ \\
\hline $\begin{array}{l}\text { A large number of medal stickers on a wine bottle is indicative of good quality } \\
\text { inside the bottle. }\end{array}$ & 3.017 \\
\hline When buying an awarded wine I can be sure to receive value for money. & 2.673 \\
\hline Wine awards help me to save time when choosing wine. & 2.817 \\
\hline Perceived ability of wine awards to reduce risk & $\mathbf{2 . 8 7 3}$ \\
\hline Serving an awarded wine indicates to my guests that I pay attention to quality. & 2.733 \\
\hline I feel that awarded wines generally taste better. & 2.750 \\
\hline Buying an awarded wine gives me some reassurance about my purchase. & 2.726 \\
\hline I generally feel confident in my purchase when buying an awarded wine. & 3.284 \\
\hline Perceived consumer benefit from wine awards & $\mathbf{3 . 2 0 0}$ \\
\hline $\begin{array}{l}\text { The increasing number of wine competitions leads wineries to produce wines } \\
\text { merely to impress judges. }\end{array}$ & 3.680 \\
\hline $\begin{array}{l}\text { The criteria at wine competitions result in wines that please the judges at the } \\
\text { expense of the consumer. }\end{array}$ & 3.430 \\
\hline Awarded wines are less easy-drinking than wines that do not carry awards. & 2.770 \\
\hline Awarded wines are often too fruit-driven and too high in alcohol for my taste. & 2.900 \\
\hline
\end{tabular}

In addition to the underlying attitudinal dimensions and statements in Table 4 above, the following underlying consumer opinions were revealed. Fifty percent (50\%) of respondents assigned more prestige to international medals, compared to medals achieved at local competitions. The annual Veritas Wine Awards are considered as the most authoritative overall, followed by the Michelangelo International Wine Awards and the Old Mutual Trophy Wine Show and Diners Club Winemaker of the Year Awards.

\section{HYPOTHESES RESULTS}

The first hypothesis formulated was to test whether the different consumer segments will attach different degrees of importance to wine awards. The null-hypothesis was formulated as follows:

$H_{1}$ : There are differences in the relative importance of wine awards between the three consumer segments. 
The results of a t-test (two-sample assuming equal variances) are shown in Table 5 below.

Table 5: $\quad$ Relative importance of wine awards

\begin{tabular}{|c|c|c|c|c|c|c|}
\hline Consumer segments & $\mathbf{N}$ & $\begin{array}{l}\text { Mean } \\
\text { value }\end{array}$ & Variance & $p$-value & F-value & $\begin{array}{l}\text { Critical } \\
\text { F-value }\end{array}$ \\
\hline Aspirational & 188 & 3.163 & 1.216 & \multirow{3}{*}{0.00000} & \multirow{3}{*}{17.71435} & \multirow{3}{*}{3.027783} \\
\hline Connoisseur & 72 & 2.314 & 1.163 & & & \\
\hline Beverage wine drinker & 25 & 3.426 & 1.384 & & & \\
\hline $\mathbf{N}$ & 285 & & & & & \\
\hline
\end{tabular}

Table 5 above shows that the $\mathrm{p}$-value of 0.00000 is smaller than 0.05 and the determined $\mathrm{F}$-value of 17.71 is larger than the critical F-value of 3.027. $\mathrm{H}_{1}$ can therefore be accepted and it can be concluded that the relative importance of wine awards in the decision-making process does indeed differ between consumer segments. As the differences in the mean values depicted in Table 5 above are significant, it can be concluded that brand managers of wine local brand should take wine awards into account when designing the marketing mix to appeal to a specific segment.

The second hypothesis formulated was to test whether the consumer segments differ in their perception that wine awards and medal stickers make a contribution in aiding decision-making. The null-hypothesis was formulated as follows:

$\mathrm{H}_{2}$ : $\quad$ There are differences in perceptions between different consumer segments regarding the contribution that wine awards and medal stickers make in aiding decision-making.

The results of a t-test (two-sample assuming equal variances) are shown in Table 6 below.

Table 6: $\quad$ Perceived ability of wine awards to act as a quality guideline

\begin{tabular}{|c|c|c|c|c|c|c|}
\hline Consumer segments & $\mathbf{N}$ & $\begin{array}{l}\text { Mean } \\
\text { value }\end{array}$ & Variance & p-value & F-value & $\begin{array}{l}\text { Critical } \\
\text { F-value }\end{array}$ \\
\hline Aspirational & 188 & 2.984 & 0.732 & \multirow{3}{*}{0.00000} & \multirow{3}{*}{20.63821} & \multirow{3}{*}{3.027783} \\
\hline Connoisseur & 72 & 2.310 & 0.586 & & & \\
\hline Beverage wine drinker & 25 & 3.240 & 0.560 & & & \\
\hline $\mathbf{N}$ & 285 & & & & & \\
\hline
\end{tabular}

From the results in Table 6 above, the p-value of 0.00000 and an F-statistic of 20.63821, which exceeds the critical F-value of $3.027783, \mathrm{H}_{2}$ can be accepted. It can be concluded that there are significant differences in perceptions between the different consumer segments regarding the contribution that wine awards and medal stickers make as a quality guide during decision-making.

The third hypothesis formulated was to test whether the importance assigned to wine awards will differ between purchasing occasions. The null-hypothesis was formulated as follows:

$H_{3}:$ The relative importance assigned to wine awards differs between purchasing occasions.

The results of a t-test are shown in Table 7 below. 
Table 7: $\quad$ The influence of purchasing occasion

\begin{tabular}{|c|c|c|c|c|c|c|}
\hline $\begin{array}{l}\text { Purchasing } \\
\text { occasions }\end{array}$ & $\mathbf{N}$ & $\begin{array}{l}\text { Mean } \\
\text { value }\end{array}$ & Variance & $p$-value & F-value & $\begin{array}{l}\text { Critical } \\
\text { F-value }\end{array}$ \\
\hline Gift_awards & 285 & 3.228 & 1.733 & \multirow{3}{*}{0.000163} & \multirow{3}{*}{8.810304} & \multirow{3}{*}{3.00629} \\
\hline Own_awards & 285 & 2.796 & 1.578 & & & \\
\hline Party_awards & 285 & 2.891 & 1.681 & & & \\
\hline
\end{tabular}

Table 7 above shows that the calculated p-value of 0.000163 is smaller than 0.05 and that the calculated F-value (8.81) is larger than the critical F-value (3.00). Therefore, $H_{3}$ can be accepted. The conclusion is therefore, that the relative importance of wine awards in shaping consumer decision-making differs significantly depending on the circumstances of the purchase.

\section{RECOMMENDATIONS TO THE SOUTH AFRICAN WINE INDUSTRY AND MARKETERS}

The following recommendations are based on the above conclusions:

- An independent authority monitoring wine awards in South Africa could enhance the value of wine awards as a marketing tool

The feeling was expressed that misconduct on the part of wine producers has undermined the value of wine awards in South Africa. Consequently, the opinion of consumers that an independent authority is needed to monitor those awards should be listened to. Wine producers themselves should initiate this process in order to preserve the value of wine awards as a marketing tool.

\section{- $\quad$ A holistic approach should be applied to wine marketing}

Rather than an isolated focus on these achievements, producers should use wine awards only to support other quality claims. First and foremost, focus should be placed on providing a desirable selection of varieties with pleasant flavour profiles, which can then be supported by claims connected to award medals.

Wine awards and medal stickers can be used to further enhance the product appeal, once those alone are unlikely to result in noticeable impact. Attention should rather be on the deliver on the important cues first, before relying on achievements at wine competitions to achieve the desired brand associations.

- Wine awards and medals should be aimed at the less informed segment

When formulating marketing communication programmes, producers need to bear in mind that only a certain portion of consumers does indeed rely on wine awards, while others - specifically connoisseurs attribute little weight to them. There is little meaning in emphasising the achievement of wine awards when talking to a consumer base that is able to make their own judgement based on other cues. However, when communicating to the lesser informed, or those who are highly risk adverse - beverage wine drinkers and aspirational drinkers - there is value in mentioning these achievements, since medal stickers do provide reassurance.

- Awards should be highlighted when marketing a wine as a "gift"

Since wine awards are given more weight when consumers buy wine as a gift, medal stickers and information pertaining to awards should be highlighted when marketing a particular wine or a wine brand as a gift. In conjunction with attractive packaging - one of the key factors when purchasing wine gifts wine awards can add value to the product and assure buyers of the quality of the product.

- Producers should not rely exclusively on medals achieved at South African competitions

It has been shown that ceteris paribus, wines with international medals are preferred over local medals. Though there does not appear to be an underlying rational argument (since methodologies are considered to be more or less of equal standards), it is advisable to allocate a reasonable amount of resources to participation in international competitions.

The individual prestige of the various international competitions requires further investigation before a specific recommendation can be made. It can nevertheless be noted that medals won at highly regarded 
international competitions should be given appropriate emphasis in the producer's marketing communication.

\section{- $\quad$ Future research on the decision-making process is needed}

Focused research is needed to investigate the decision-making process in the wine category and to identify factors that could lead to an improvement of the value of wine awards as a marketing tool.

\section{CONCLUSION}

It is clear from the results that the increasing number of wine competitions appears to dilute the value of wine awards as a marketing tool and that consumers are sceptical about the honesty of producers in marketing their awards.

A few industry-specific issues undermine the value and potential impact of wine awards as a marketing tool and an independent monitoring authority is suggested as a solution to raise the profile of wine awards in South Africa. Such an institution could enhance the credibility and the value of wine awards for producers and consumers alike.

\section{LIST OF REFERENCES}

Aaker, D., Kumar, V. \& Day, G. 2000. Marketing Research. Seventh Edition. New York, NY: John Wiley \& Sons, Inc.

Churchill, G. A. \& lacobucci, D. 2005. Marketing Research. Methodological Foundations. Ninth Edition. Mason, $\mathrm{OH}$ : Thomson South-Western.

Joubert, L. 2005. Playing the competition lottery. Wineland, July. Available online: http://www.wineland.co.za/2005july-comp.php3. [Accessed: 13 November 2007].

Lockshin, L. \& Hall, J. 2003. Consumer purchasing behaviour for wine: What we know and where we are going. International Wine Marketing Colloquium, Adelaide, July, CD-ROM.

Lockshin, L., Jarvis, W., d'Hauteville, F. \& Perrouty, J. P. 2006. Using simulations from discrete choice experiments to measure consumer sensitivity to brand, region, price and awards in wine choice. Food Quality and Preference, 17, 166 - 178.

McGregor, A. 2007. The rich are intoxicated by wine making. Sunday Times, October 7.

Minaar, M. 2005. Gold stickers: Leading and misleading. Grape, 30 June. Available online: http://www.grape.co.za/Viewsarchive/050606goldstickers.htm [Accessed: 13 November 2007]

Mitchell, V. and Greatorex, M. 1989. Risk reducing strategies used in the purchase of wine in the UK. European Journal of Marketing, 23 (9), 31 - 46.

Orth, U.R. 2002. Research note. Targeting the un-experienced and convenience shopper. International Journal of Wine Marketing, 14 (3), 80 - 82.

Orth, U. R. \& Krska, P. 2002. Quality signals in wine marketing: The role of exhibition awards. International Food and Agribusiness Management Review, 4, 385 - 397.

Patten, M. L. 2001. Questionnaire Design. A Practical Guide. Los Angeles, CA: Pyrczak Publishing.

Pendock, N. 2006. Wine competitions - An overtraded market? Available online: http://www.wine.co.za/News/News.aspx?NEWSID=7950\&Source=News [Accessed: 8 October 2007].

Saunders, M., Lewis, P. \& Thornhill, A. 2007. Research Methods for Business Students. Fourth Edition. London: Prentice Hall.

Spawton, T. 1991. Marketing planning for wine. European Journal of Wine Marketing, 25 (3), 1 - 48. 
Thomas, A. 2000. Elements influencing wine purchasing: A New Zealand view. International Journal of Wine Marketing, 12 (2), $47-62$.

Van Zyl, P. (Ed). 2006. John Platter Wine Guide. Injectrade 25, Cape Town.

www.veritas.co.za. Veritas Wine Awards. [Accessed: 6 October 2007]. 